\section{GRUPO DE GESTANTES: CONTRIBUIÇÕES E POTENCIALIDADES NA COMPLEMENTARIDADE DA ASSISTÊNCIA PRÉ-NATAL}

\author{
Group of pregnant women: contributions and potential \\ complementarity of prenatal care
}
Grupo de embarazadas: contribuciones y potencialidades en la complementariedad de la atención prenatal

\section{RESUMO}

Objetivo: Verificar as contribuições e potencialidades de um grupo de gestantes enquanto subsídio complementar à assistência pré-natal. Métodos: Trata-se de um estudo de natureza exploratória, com abordagem qualitativa, desenvolvido em um grupo de gestantes do município de Picuí-PB. Participaram do estudo oito gestantes, sendo os dados coletados entre os meses de julho e setembro de 2012, por meio de um roteiro semiestruturado, e analisados segundo a técnica do Discurso do Sujeito Coletivo (DSC). Resultados: Os discursos evidenciaram o conhecimento das mulheres acerca do significado de grupo de gestantes, como o também o complemento que este representa na assistência pré-natal e a melhor vivência da gravidez, em decorrência da participação nas reuniões do grupo, permitindo a socialização da vivência gestacional e as trocas de experiências e conhecimentos entre as participantes. Conclusão: O grupo atuou como uma ferramenta complementar eficaz para o pré-natal, à medida que permitiu uma vivência mais segura e informada do ciclo gravídicopuerperal. É preciso incentivar a disseminação dos grupos de gestantes, a fim de tornar as mulheres ativas no processo gestatório.

Descritores: Gestantes; Cuidado Pré-Natal; Atenção Primária à Saúde; Prática de Grupo; Promoção da Saúde.

\section{ABSTRACT}

Objective: To assess the contributions and potentialities of a Group of Pregnant Women as a complementary subsidy to prenatal care. Methods: This is a study of exploratory nature, with qualitative approach, developed in a group of pregnant women in the city of Picui, PB, Brazil. The study included eight pregnant women. Data was collected between July and September 2012, through a semi-structured interview, and analysed according to the Collective Subject Discourse (CSD) technique. Results: The speeches evidenced the women's knowledge about the meaning of a group of pregnant women, as well as the complementarity that this represents within prenatal care, and the improved experience of pregnancy in result of the participation in group meetings, enabling socialization of the gestational experience, and experience and knowledge exchanges between the participants. Conclusion: The group acted as an effective complementary tool for prenatal care, as it allowed a safer and more informed experience of the pregnancy-puerperium cycle. It is necessary to encourage the dissemination of pregnant women groups in order to render women active in the process of pregnancy.

Descriptors: Pregnant Women; Prenatal Care; Primary Health Care; Group Practice; Health Promotion.
Artigo Original

Janaína Von Söhsten Trigueiro(1) Alynne Mendonça Saraiva ${ }^{(1)}$ Monise Gleyce de Araújo Pontes $^{(2)}$

Joseane da Rocha Dantas Cavalcanti $^{(2)}$ Rosilene Santos Baptista ${ }^{(3)}$

1) Universidade Federal de Campina Grande - UFCG - campus Cuité - Cuité (PB) - Brasil

2) Universidade Federal do Rio Grande do Norte - UFRN - Natal (RN) - Brasil

3) Universidade Estadual da Paraíba UEPB - Campina Grande (PB) - Brasil

Recebido em: 27/06/2014 Revisado em: $11 / 08 / 2014$ Aceito em: 30/11/2014 


\section{RESUMEN}

Objetivo: Verificar las contribuciones y las potencialidades de un grupo de embarazadas como subsidio complementario de la atención prenatal. Métodos: Se trata de un estudio de naturaleza exploratoria de abordaje cualitativo desarrollado con un grupo de embarazadas del municipio de Picui-PB. Ocho embarazadas participaron del estudio que tuvo los datos recogidos entre los meses de julio y septiembre de 2012 a través de una guía semiestructurada y analizados según la técnica del Discurso del Sujeto Colectivo (DSC) Resultados: Los discursos evidenciaron el conocimiento de las mujeres sobre el significado de grupo de embarazadas así como el complemento que lo mismo representa para la atención prenatal y mejor vivencia del embarazo decurrente de la participación en las reuniones del grupo que permiten la socialización de la experiencia de la gestación y los cambios de experiencia y conocimientos de las participantes. Conclusión: El grupo fue una herramienta complementaria eficaz para el prenatal al paso que permitió una vivencia más segura e informada del ciclo gravido-puerperal. Es necesario el incentivo de la diseminación de grupos de embarazadas para hacer de las mujeres personas más activas en el proceso de la gestación.

Descriptores: Mujeres embarazadas; Atención Prenatal; Atención Primaria de Salud; Practica de Grupo; Promoción de la Salud.

\section{INTRODUÇÃO}

A gestação e seu contexto são caracterizados por diversos sentimentos, dúvidas, anseios, medos, emoções e angústias, fazendo-se necessário que as mulheres tenham um acompanhamento integral e de qualidade para além das mudanças físicas que acontecem com seu corpo, a fim de que possam ser escutadas e esclarecidas sobre tudo que as aflige e vivenciem esse momento da melhor forma possível, tornando-se ativas nesse processo ${ }^{(1,2)}$.

A assistência pré-natal constitui-se em: cuidados, condutas e procedimentos visando promover a saúde do binômio materno-infantil; identificar, tratar ou controlar patologias; prevenir complicações na gestação e parto; assegurar a boa saúde materna; promover o bom desenvolvimento fetal; reduzir os índices de morbimortalidade materna e fetal; e preparar o casal para o exercício da paternidade ${ }^{(3,4)}$.

O acompanhamento deve ser iniciado o mais precocemente possível, ainda no primeiro trimestre, devendo ser regular e completo. Preconiza-se a realização de no mínimo seis consultas, sendo uma no primeiro trimestre, duas no segundo e três no último trimestre ${ }^{(4,5)}$. A assistência pré-natal não pode se restringir apenas às ações clínico-obstétricas, pois há todo um contexto característico do período gestacional em volta da mulher que precisa ser assistido, reconhecido e aprofundado pelos profissionais de saúde que a acompanham, buscando entendê-la e assisti-la integralmente ${ }^{(5)}$.

Uma atenção qualificada e humanizada, portanto, dáse por meio da incorporação de condutas acolhedoras e sem intervenções desnecessárias; do fácil acesso a serviços de saúde de qualidade, com ações que integrem todos os níveis da atenção: promoção, prevenção e assistência à saúde da gestante e do recém-nascido, desde o atendimento ambulatorial básico ao atendimento hospitalar para alto $\operatorname{risco}^{(3,4)}$.

Porém, atualmente, as consultas de pré-natal têm se tornado cada vez mais rápidas e tecnicistas, ocorrendo fragmentação da assistência e, principalmente, das atividades de educação em saúde; sem escuta qualificada e diálogo aberto focados nas necessidades das gestantes, predominando a passividade da usuária no processo gestatório, desconsiderando todo o saber que esta possui, e, consequentemente, deixando a desejar na assistência ofertada à mulher ${ }^{(6,7)}$.

A falta de acolhimento e vínculo, o uso indiscriminado de tecnologias e intervenções desnecessárias, a diminuição da autonomia e a expropriação do direito de serem sujeitos principais nesse processo geram descontentamento por parte das mulheres, bem como afetam na qualidade e humanização da assistência ${ }^{(7,8)}$.

Faz-se necessário, portanto, que cada vez mais se busque pela qualidade das consultas de pré-natal, visto que ainda nos deparamos com elevadas taxas de morbimortalidade materna e perinatal nos dias de hoje, conforme o Relatório do Ministério da Saúde do ano de $2009^{(9)}$.

Ressalta-se nesse documento que, no Brasil, mais da metade das mortes maternas e neonatais ocorrem durante a internação da mulher para o parto e nascimento, com $70 \%$ das mortes por causas obstétricas diretas, $15 \%$ das mortes decorrentes de aborto inseguro, $51 \%$ das mortes neonatais na primeira semana de vida e relacionadas majoritariamente com problemas decorrentes do parto. Para cada morte materna, outras trinta mulheres sofrem sequelas ou problemas crônicos de saúde decorrentes de complicações ocorridas durante a gravidez, parto ou pós-parto. Esses dados apontam, portanto, para uma reorganização da atenção não só no pré-natal, como também em todo o ciclo gravídicopuerperal, sob a lógica da longitudinalidade do cuidado, da integralidade e da humanização da assistência ${ }^{(5,7-12)}$.

De forma a complementar e subsidiar a assistência oferecida nas consultas de pré-natal, e com o objetivo de tornar eficaz a qualidade dos serviços prestados pelas Unidades de Saúde, surgem os grupos de gestantes, espaços dinâmicos que objetivam promover a saúde das gestantes de forma integral, individual e coletivamente, envolvendo gestante, família e comunidade ${ }^{(13,14)}$. 
As atividades desenvolvidas em grupo ganham importância a ponto de ajudar pessoas durante períodos de ajustamentos e mudanças, e na manutenção ou adaptação a novas situações, promovendo o desenvolvimento das pessoas, potencializando conhecimentos que as possibilitam cuidar de sua saúde de acordo com as necessidades que enfrentam e conscientizando da maternidade e paternidade responsáveis, entendendo que o pai pode e deve ser participativo nos encontros ${ }^{(14)}$.

De maneira geral, os grupos de gestantes são desenvolvidos com a finalidade de complementar o atendimento realizado nas consultas, assistindo às mulheres em todo o seu contex to biopsicossocial; melhorar a aderência das gestantes aos hábitos considerados mais adequados; diminuir a ansiedade e compreender de forma mais clara os sentimentos que surgem nesse período, permitindo a aproximação entre profissionais e receptores do cuidado; além de favorecer um espaço para a troca de conhecimentos e vivências entre os participantes ${ }^{(15,16)}$.

Diante do exposto, a presente pesquisa enfatizou o grupo de gestantes como objeto de estudo a partir da perspectiva de mulheres participantes desse espaço de saberes, elencando a promoção da saúde desse público como pressuposto deste estudo.

$\mathrm{Na}$ tentativa de valorizar a temática e gerar discussões voltadas às contribuições e potencialidades inerentes a essa estratégia complementar do pré-natal, esta pesquisa teve como objetivo verificar as contribuições e potencialidades de um grupo de gestantes enquanto subsídio complementar a assistência pré-natal.

\section{MÉTODOS}

Tratou-se de um estudo de natureza exploratória, sob a perspectiva da abordagem qualitativa, desenvolvido em um grupo de gestantes do município de Picuí-PB, cujas reuniões foram realizadas mensalmente, com participação de gestantes acompanhadas pelas Unidades Básicas de Saúde (UBS) do referido município, com cerca de 20 a 30 participantes por encontro. O município conta com oito UBS, sendo quatro localizadas na zona urbana e quatro na zona rural, sendo estas últimas mais precárias no que concerne aos recursos humanos, materiais e de infraestrutura.

Neste estudo, a população foi composta por todas as mulheres que participavam das reuniões do grupo local, e a amostra totalizou oito gestantes, sendo constituída por aquelas que se enquadravam como maiores de 18 anos e tinham frequência mínima de três encontros no grupo, para a melhor qualidade e contribuição dos relatos. Todas aceitaram participar livremente da pesquisa, assinando o Termo de Consentimento Livre e Esclarecido (TCLE).
O material analisado, por sua vez, foi obtido a partir de dados primários coletados entre os meses de julho e setembro de 2012, por meio de um roteiro semiestruturado. As entrevistas foram registradas fazendo uso de um aparelho gravador de som, para que fosse possível, posteriormente, a transcrição na íntegra de todas as falas das participantes da pesquisa.

O roteiro semiestruturado foi composto por duas partes, sendo a primeira delas referente aos dados obstétricos das gestantes, abordando variáveis como faixa etária, quantidade de gestações, partos normais, cesarianas e abortamentos. Para atingir os objetivos da pesquisa, na segunda parte do roteiro, foram levadas em consideração as seguintes questões norteadoras do estudo: como você classifica os encontros do grupo de gestante? Quais os temas abordados no grupo? Qual o significado de "grupo de gestante" para você? De que forma você acha que o grupo complementa a assistência pré-natal que você recebeu? Você acredita que sua participação nas reuniões do grupo favoreceu uma melhor vivência da gravidez?

No que concerne à coleta dos dados relacionados aos temas abordados no grupo de gestantes, ela se deu mediante um check-list com o nome de diversas temáticas, que vão desde a importância da amamentação, modificações corporais e emocionais da mãe, preparo para o momento do parto, cuidados com o recém-nascido até temas como importância do pai e familiares no ciclo gravídicopuerperal, vacinação da gestante e da criança, orientação quanto à higiene, atividade física e sexualidade na gravidez, existindo ainda uma opção com "outros" e um espaço para que as mulheres relatassem qualquer outra temática que não constava no check-list. Com relação à questão "como você classifica os encontros do grupo de gestante?", as gestantes tiveram como opções de resposta: regular, bom e ótimo.

Os dados obstétricos, classificação e check-list foram apresentados em forma de texto descritivo, valorizando as principais informações coletadas e analisadas com base no enfoque do método qualitativo, à luz da literatura pertinente.

O material obtido das demais questões norteadoras foi apresentado através de quadros com ideias centrais para cada pergunta, analisado de acordo com a técnica do Discurso do Sujeito Coletivo (DSC) e, posteriormente, discutido à luz da literatura pertinente. O DSC é um método que retrata as expressões das falas dos pesquisados, em síntese e em primeira pessoa do singular, o que representa o pensamento coletivo em uma única fala e possibilita interpretações para fundamentar resultados ${ }^{(17)}$.

A obtenção de descrições de pensamentos, crenças e valores de forma coletiva se deu através da soma de discursos individuais, por intermédio do método do DSC, um procedimento metodológico, de corte qualitativo, 
próprio de pesquisas sociais empíricas, que consiste numa forma qualitativa de representar o pensamento de uma coletividade. Isso só é possível através da agregação das figuras metodológicas (ideias centrais, ancoragens, expressões-chave e DSC) de sentido semelhante, num só discurso-síntese, emitidas por pessoas distintas, como respostas a perguntas abertas de questionário ${ }^{(17)}$.

Dessa forma, os discursos individuais das gestantes foram lidos e identificados por uma palavra, conceito ou expressão que revelasse a essência do sentido da resposta. Essa palavra representou bem tais depoimentos, nos quais foram enquadrados vários discursos com ideias semelhantes.

Foram considerados os aspectos éticos contidos na Resolução 466/12 do Conselho Nacional de Saúde, acerca das diretrizes e normas regulamentadoras de pesquisas envolvendo seres humanos, e na Resolução 311/2007 do Conselho Federal de Enfermagem - COFEN, que trata do Código de Ética dos Profissionais de Enfermagem ${ }^{(18,19)}$, obtendo a autorização para a realização da pesquisa pelo Comitê de Ética em Pesquisa (CEP) da Faculdade de Enfermagem Santa Emília de Rodat (FASER), sob o número 066/2011.

\section{RESULTADOS E DISCUSSÃO}

Para a explanação dos resultados deste estudo, inicialmente, serão apresentados os dados obstétricos das participantes e, em seguida, os dados obtidos das questões norteadoras da pesquisa.

Com relação à faixa etária das participantes deste estudo, do total de oito mulheres, cinco eram menores de 23 anos, duas tinham entre 24 e 28 anos e apenas uma mulher tinha idade entre 29 e 32 anos. Para as mulheres que já haviam vivenciado gestações anteriores, sendo o equivalente a seis das entrevistadas, três fizeram cesárea e as outras três, parto normal. O restante das participantes, ou seja, duas, vivenciavam a gestação pela primeira vez.

De acordo com a distribuição de faixa etária e número de gestações das colaboradoras deste estudo, é notória uma maior incidência de mulheres jovens grávidas e que já vivenciaram o período gestacional mais de uma vez. Tais resultados vão ao encontro dos dados atuais, que representam a alta incidência de gravidez na adolescência, especialmente nas camadas mais pobres da população, em decorrência, geralmente, do pouco acesso à informação quanto aos métodos contraceptivos e ao planejamento familiar, configurando-se em um problema de saúde pública $^{(20)}$.

Segundo a Pesquisa Nacional sobre Demografia e Saúde (PNDS), realizada em 1996, 18\% das adolescentes brasileiras de 15 a 19 anos já tiveram pelo menos um filho ou estavam grávidas, e segundo dados do Instituto Brasileiro de Geografia e Estatísticas (IBGE), mais de $20 \%$ de todas as crianças brasileiras nascem de mães adolescentes. Nos estudos dos fatores associados às causas e consequências dessa gravidez, é necessário considerar que se trata de um fenômeno complexo, associado a fatores econômicos, educacionais e comportamentais, como desigualdade social e econômica, início precoce da vida sexual, história materna de gravidez na adolescência, prénatal inadequado, não utilização ou utilização inconsistente de métodos contraceptivos e uso frequente de drogas ilícitas por familiares ${ }^{(20-23)}$.

As altas taxas de gravidez na adolescência no Brasil sinalizam que uma em cada cinco brasileiras tem o primeiro filho antes dos 20 anos de idade. Tal cenário traz consigo aspectos negativos, pois está relacionado à maior ocorrência de prematuridade e baixo peso ao nascer e prénatal inadequado, o que acarreta menor número de consultas de pré-natal, início das consultas mais tardiamente e baixa realização de exames complementares. Somam-se a esses fatores a falta de informações sobre os benefícios do prénatal e o sentimento de vergonha pela busca de cuidados por parte das adolescentes, sobretudo entre as mais pobres. Além disso, elas amamentam seus filhos por um menor período de tempo. Todo esse contexto resulta em maior mortalidade infantil entre seus filhos ${ }^{(24,25)}$.

No que concerne à equivalência entre os tipos de parto - normal e cesárea -, podemos perceber que os dados diferem de outros estudos cujos índices de cesarianas são bem maiores. Tal fato pode ser justificado, pois o estudo foi realizado numa cidade interiorana, na qual o acesso a tecnologias de suporte avançado em obstetrícia é limitado, o que pode ter influenciado os resultados obtidos.

O Brasil apresenta uma das taxas de cesáreas mais altas do mundo e tem sido citado como exemplo claro do abuso desse procedimento, chegando a índices bem maiores na rede privada $(80 \%)$ quando comparados aos serviços públicos $(35 \%)$. Tal fato ocorre por razões mais relacionadas a fatores socioeconômicos e culturais, bem como a preferências de médicos e parturientes, do que propriamente em decorrência de riscos obstétricos e condições clínicas adversas ${ }^{(26-28)}$.

Esse índice abusivo de cesariana ultrapassa as proporções de $10 \%$ a $15 \%$ recomendado pela Organização Mundial da Saúde (OMS) em 1985, cuja tendência de crescimento vem se consolidando nos últimos anos. Estimase que no Brasil, onde nascem 2,5 milhões de crianças por ano, haja 560 mil cesáreas desnecessárias que consomem quase R \$ 84 milhões, prejuízo para além do financeiro que perpassa pela cultura de vias de nascimento disseminadas em nosso país ${ }^{(26-29)}$. 
Sendo o abortamento a interrupção da gravidez ou expulsão (espontânea ou provocada) do feto de até 22 semanas de idade gestacional (IG), ou que o concepto morto tenha pesado menos de $500 \mathrm{~g}$ ou medido menos de 16 centímetros $^{(30)}$, ao questionarmos sobre situações de abortamento vivenciadas pelas participantes desta pesquisa, o quantitativo encontrado foi mínimo, pois apenas uma participante afirmou ter vivenciado tal episódio, segundo a qual, de forma espontânea.

Esse representativo pode estar atrelado às restrições legais ao aborto provocado no Brasil, impedindo muitas vezes a veracidade dos dados, visto que, de acordo com o Código Penal Brasileiro, a interrupção da gravidez só é permitida em caso de estupro, risco de vida para a mãe e, mais recentemente, em situações de anomalias fetais severas, como anencefalia (ausência de cérebro), sob autorização judicial ${ }^{(20,31)}$. Porém, a ilegalidade não impede que abortos sejam realizados, o que contribui para o emprego de técnicas inseguras e restringe a confiabilidade das estatísticas sobre essa prática.

Como justificativa dessa contradição, pesquisadores garantem que o abortamento deve ser uma prioridade na agenda de saúde pública no Brasil, visto que, de acordo com a Pesquisa Nacional de Aborto (PNA), um levantamento por amostragem aleatória de domicílios realizado em 2010 com mulheres entre 18 e 39 anos em todo o Brasil urbano, mais de uma em cada cinco mulheres já realizou um aborto, geralmente nas idades que compõem o centro do período reprodutivo das mulheres (entre 18 e 29 anos), principalmente entre mulheres de menor escolaridade ${ }^{(31)}$.

Tratando-se da classificação dos encontros vivenciados no grupo de gestantes, tendo como opções ótimo, regular e bom, todas as entrevistadas avaliaram os encontros como sendo ótimo, o que indica, a princípio, a eficácia do grupo em estudo. A relevância do trabalho em grupo refere-se à positiva contribuição na promoção da saúde dos participantes, bem como ao benefício dos membros, por permitir a troca de experiências entre eles e o conhecimento com informações passadas pelos profissionais de saúde, complementando o saber particular de cada indivíduo ${ }^{(13-15)}$.

A partir do fato de as colaboradoras deste estudo considerarem os encontros como ótimos, infere-se que o grupo de gestantes é uma estratégia importante na promoção da saúde materna, tendo em vista a contribuição das informações e trocas de experiências nele compartilhadas, permitindo uma vivência mais segura e orientada das participantes em suas gestações, bem como uma assistência de qualidade e humanizada ao binômio mãe-filho.

Segundo o Ministério da Saúde, o desenvolvimento do grupo de gestantes é considerado um recurso importante para promover o atendimento individualizado e integral das necessidades da mulher grávida, de seu parceiro e das demais pessoas envolvidas, com a finalidade de complementar o atendimento realizado nas consultas, melhorar a aderência das mulheres aos hábitos considerados mais adequados e diminuir ansiedades e medos relativos ao período gravídicopuerperal $^{(3)}$.

Diversas temáticas foram abordadas nos encontros do grupo em que as entrevistadas estavam presentes, cada uma com sua devida importância, reafirmando a complementaridade dessa estratégia para o acompanhamento pré-natal. Porém, os temas mais vivenciados por elas dizem respeito à importância da amamentação, ao preparo para o momento do parto e aos primeiros cuidados com o recémnascido.

É fundamental trabalhar a temática da amamentação em grupo de gestantes, visto que o aleitamento materno, além de nutrir e fornecer anticorpos necessários à proteção do bebê contra diversas doenças, é uma forma de estabelecer um vínculo afetivo e de segurança entre mãe e filho; além disso, é prático e econômico. Em razão dos vários mitos, crenças e constatações acerca da amamentação, esse contexto deve ser conhecido e compreendido pelos profissionais de saúde envolvidos no pré-natal da gestante, para melhor orientá-la sobre a importância da amamentação ${ }^{(32)}$.

O preparo para o momento do parto, enfatizando a valorização do parto natural, por via vaginal, é apontado pelas entrevistadas como uma opção segura e favorável ao binômio mãe-filho. A desmistificação do "parto normal" enquanto momento doloroso para a mãe é vista aqui como um fator imprescindível para o esclarecimento das participantes referente à escolha do tipo de parto que gostariam de vivenciar, devendo ser a cesariana uma via seletiva de urgência para casos específicos, quando há riscos para a saúde da mãe e/ou do filho.

As atividades educativas junto às gestantes a serem realizadas em grupo ou individualmente devem, portanto, ter uma linguagem clara e compreensível, a fim de promoverem orientações gerais sobre os cuidados na gestação, alterações fisiológicas e emocionais, cuidados com o recém-nascido, amamentação e planejamento familiar, assim como envolver o pai, respeitando a cultura e o saber popular para facilitar a participação ativa da mulher durante o parto ${ }^{(33)}$.

Além do mais, as ações educativas durante o pré-natal no grupo de gestantes podem ainda abordar uma variedade de temas, como a importância do acompanhamento pré-natal, alimentação saudável, cuidados de higiene, cuidados com as mamas, atividade física, sexualidade, benefícios legais a que a mulher tem direito, importância do planejamento familiar, importância do acompanhamento do crescimento e desenvolvimento da criança, e abordar questões escolhidas pelas próprias participantes ${ }^{(34,35)}$. 
Quadro I - Discurso do Sujeito Coletivo em resposta à pergunta: qual o significado de grupo de gestantes para você? Picuí-PB, 2012.

\begin{tabular}{|c|c|}
\hline Ideia Central - 1 & Discurso do Sujeito Coletivo \\
\hline $\begin{array}{l}\text { Espaço de } \\
\text { Conhecimento e } \\
\text { Informação }\end{array}$ & $\begin{array}{l}{[\ldots] \text { O grupo de gestantes é onde }} \\
\text { as gestantes se reúnem junto com } \\
\text { os profissionais da saúde para dar } \\
\text { informações... já que no pré-natal não } \\
\text { pode oferecer, até porque não tem } \\
\text { tempo suficiente... o que é bastante } \\
\text { importante }[. . .]\end{array}$ \\
\hline Ideia Central - 2 & Discurso do Sujeito Coletivo \\
\hline $\begin{array}{l}\text { Espaço de Troca } \\
\text { de Experiências }\end{array}$ & $\begin{array}{l}\text { [...] É um grupo de mulheres } \\
\text { na mesma situação, no período } \\
\text { gestacional, que estão ali querendo } \\
\text { ficar mais bem esclarecidas a respeito } \\
\text { das suas gestações. Assim, cada uma } \\
\text { que tem uma experiência diferente } \\
\text { pra conversar uma com a outra, pra } \\
\text { compartilhar, quem sabe mais ensina } \\
\text { a quem não sabe nada. Ele serve, } \\
\text { justamente, pra fazer essa troca de } \\
\text { experiências. Lá eu aprendi muito } \\
{[\ldots]}\end{array}$ \\
\hline
\end{tabular}

Os Discursos dos Sujeitos Coletivos (DSC), elaborados no Quadro I, levam-nos a reconhecer o grupo de gestantes em questão como um espaço de conhecimento e informação (Ideia Central 1) e como um espaço de troca de experiências (Ideia Central 2).

Sendo os grupos constituídos de pessoas com histórias de vida distintas, mas com interesses semelhantes, que se reúnem para refletir criticamente sobre temas comuns, podendo no coletivo construir saberes conjuntos, superar suas limitações e reconhecer seus papéis sociais, o grupo de gestantes é visto como um espaço de conhecimento e obtenção de novas informações, de trocas de experiências e de vínculos entre os participantes, contribuindo positivamente para a vivência do período gestacional ${ }^{(36)}$.

Nessa perspectiva, o grupo atua como um ambiente que, ao mesmo tempo, é interdisciplinar, interativo, dinâmico e complexo; direcionado à promoção da saúde, ao cuidado humanizado e à autonomia dos seus integrantes ${ }^{(36)}$, ajudando cada participante a enfrentar as situações de mudança, "resignificando" suas vivências através do reconhecimento dos outros e de $\mathrm{si}^{(37)}$.
Quadro II - Discurso do Sujeito Coletivo em resposta à pergunta: de que forma você acha que o grupo complementa a assistência pré-natal que você recebeu? Picuí-PB, 2012.

\begin{tabular}{|l|l|}
\hline Ideia Central -1 & Discurso do Sujeito Coletivo \\
\hline & $\begin{array}{l}{[\ldots] \text { Complementou com várias }} \\
\text { informações muito importantes } \\
\text { como, por exemplo, sobre a } \\
\text { amamentação (..) hora do parto } \\
\text { C o m p l e m e n t o } \\
\text { Informativo } \\
\text { emocionais da mãe (..) cuidados } \\
\text { gerais e higiene da criança [...] }\end{array}$ \\
\hline Ideia Central -2 & Discurso do Sujeito Coletivo \\
\hline & $\begin{array}{l}\text { [...] As reuniões esclareceu muitas } \\
\text { coisas. Indo para as palestras, } \\
\text { retirei várias dúvidas, porque tinha } \\
\text { muita coisa que eu não sabia, } \\
\text { então trouxe muitas respostas, } \\
\text { informações que eu não tinha. Me } \\
\text { deu muita segurança, me achei } \\
\text { muito segura depois que eu fui } \\
\text { para o grupo [...] }\end{array}$ \\
\hline
\end{tabular}

Os discursos formulados no Quadro II, com base na fala das entrevistas, remetem-nos ao grupo de gestantes em estudo como sendo um complemento à assistência prénatal, por vezes informativo (Ideia Central 1), bem como esclarecedor (Ideia Central 2).

A primeira ideia central tem o complemento informativo embasado na premissa de autores que afirmam ser a convivência grupal a possibilidade de geração de conhecimentos com base na troca de saberes de cada participante do grupo, e não só por parte dos profissionais de saúde, tornando ativos os sujeitos envolvidos no grupo, a ponto de expressarem suas necessidades, expectativas, opiniões, angústias e vivências ${ }^{(38)}$.

A segunda ideia central propicia uma visão do grupo de gestantes como complemento esclarecedor, retirando dúvidas, dando respostas e passando tranquilidade e segurança às participantes. Assim, salienta-se que atividades grupais com gestantes remetem a uma melhor vivência da mulher no processo gravídico-puerperal, no momento em que ela passa a conhecer melhor tanto a si mesma como também ao feto que cresce em seu ventre ${ }^{(37)}$.

O grupo, portanto, possibilita o intercâmbio de experiências, informações e conhecimentos, por isso é considerado a melhor forma de promover a compreensão do processo de gestação, em que informações sobre as 
diferentes vivências devem ser trocadas entre as mulheres, parceiros e profissionais de saúde, estimulando a presença e participação do pai no pré-natal e nos encontros ${ }^{(4,13)}$.

Quadro III - Discurso do Sujeito Coletivo em resposta à pergunta: você acredita que sua participação nas reuniões do grupo favoreceu uma melhor vivência da gravidez? Picuí-PB, 2012.

\begin{tabular}{|l|l|}
\hline Ideia Central & Discurso do Sujeito Coletivo \\
\hline & $\begin{array}{l}{[. .] \text { Favoreceu muito na minha }} \\
\text { gravidez (...) ficar super informada } \\
\text { das coisas da gravidez que eu não } \\
\text { sabia, e lá eu aprendi muito, foi }\end{array}$ \\
Favorecimento \\
positivo & ótimo, muito bom, muito bom \\
& mesmo. Na próxima gravidez \\
& estarei lá em todas as reuniões [...] \\
\hline
\end{tabular}

De acordo com o DSC construído e representado no Quadro III, as participantes deste estudo acreditam que a participação no grupo foi de extrema importância e com repercussões positivas para a vivência do período gestacional e maternidade, uma vez que o grupo de gestantes traz aspectos terapêuticos e de suporte, por meio das informações, dos conhecimentos e das trocas de experiências entre as participantes.

O grupo dá a possibilidade de manifestação de dúvidas e dificuldades de cada um, pois os participantes podem dizer seus problemas e refletir sobre eles. Ter ideia das situações futuras da gestação e mesmo daquilo que ocorrerá após ela trará a essas gestantes bem-estar e tranquilidade, prevenindo ansiedades desnecessárias provocadas pelo desconhecimento das situações próprias da gravidez, parto e puerpério ${ }^{(13,14,16)}$.

De maneira geral, os grupos de gestantes atuam com o objetivo de complementar a assistência oferecida nas consultas de pré-natal, contribuindo para o bem-estar geral das mulheres, de modo que elas expressam suas necessidades, resultando em seu interesse e envolvimento em relação aos temas abordados, levando à compreensão mais profunda dos assuntos discutidos e a uma avaliação positiva do processo.

Dessa forma, o grupo tem contribuído cada vez mais para que suas participantes tenham uma melhor vivência da gravidez, do momento do parto e do período pós-parto, e, consequentemente, no preparo para a maternidade, paternidade e formação da nova família com a chegada do filho.

Uma das limitações deste estudo foi o pequeno número de participantes, mas isso se justifica pela saturação dos resultados obtidos com as respostas das entrevistadas e, principalmente, pelo fato de a população em estudo não corresponder a todos os critérios de inclusão préestabelecidos, com ênfase na condição mínima de ter participado de três encontros no grupo - muitas das mulheres participaram apenas de uma ou duas reuniões.

\section{CONSIDERAÇÕES FINAIS}

Ao final do estudo, percebemos que o grupo de gestantes atuante no município pesquisado contribui de forma significativa enquanto subsídio complementar na qualidade da assistência pré-natal oferecida pelas Unidades Básicas de Saúde às gestantes dessa cidade.

As ações realizadas no grupo trouxeram, de forma geral, impactos positivos para o bem-estar das participantes. Não foram apontadas fragilidades pelas colaboradoras, pois, para a maior parte delas, o grupo significou um espaço de conhecimento, informação e troca de experiências.

Os discursos dos sujeitos coletivos, formulados a partir das falas individuais de cada colaboradora deste estudo, evidenciaram o conhecimento delas acerca do significado de grupo de gestantes, como também o complemento que este representa na assistência pré-natal e na melhor vivência da gravidez, em decorrência da participação nas reuniões do grupo.

Para tanto, é pertinente que o processo educativo seja parte fundamental da assistência à saúde no pré-natal, de modo que permita à gestante, por meio dos conhecimentos adquiridos, tornar-se ativa no processo de gestar e, consequentemente, empoderar-se de si mesma em seu autocuidado e no processo de cuidar da criança.

No que concerne à limitação encontrada no desenvolvimento desta pesquisa, aponta-se para o pequeno quantitativo da amostra, tendo em vista o enquadramento das gestantes participantes do grupo aos critérios de inclusão pré-estabelecidos. Porém, mesmo assim, ao final deste estudo, com o alcance do objetivo estabelecido, identificamos a importante colaboração do grupo de gestantes em questão para uma vivência mais segura e informada do ciclo gravídico-puerperal das participantes. Valorizamos aqui o trabalho desenvolvido nesse espaço e reafirmamos a complementariedade que o grupo apresenta para a assistência pré-natal oferecida às gestantes dessa comunidade.

Diante do exposto, espera-se que esta pesquisa traga contribuições para o aprimoramento e desenvolvimento do conhecimento científico sobre a importância dos grupos de gestantes como subsídio complementar à assistência prénatal. Com isso, espera-se que este estudo se torne uma ferramenta de divulgação desses grupos, incentivando outras pesquisas a serem desenvolvidas, tendo em vista 
não só a relevância científica que apresenta, mas também a relevância social diante da assistência oferecida às gestantes, seus parceiros e familiares.

\section{REFERÊNCIAS}

1. Cabral FB, Oliveira DLLC. Women's vulnerability in the puerperium from the view of Family Health Teams: emphasis on generational aspects and adolescence. Rev Esc Enferm USP. 2010; 44(2):368-75.

2. Camacho KG, Vargens OMC, Progianti JM, Spíndola T. Vivenciando repercussões e transformações de uma gestação: perspectivas de gestantes. Cienc Enferm. 2010;16(2):115-25.

3. Ministério da Saúde (BR), Secretaria de Atenção à Saúde, Departamento de Atenção Básica. Atenção ao pré-natal de baixo risco. $1^{\text {a }}$ ed. rev. Brasília: Ministério da Saúde; 2013.

4. Ministério da Saúde (BR), Secretaria de Atenção à Saúde, Departamento de Ações Programáticas Estratégicas, Área Técnica de Saúde da Mulher. Prénatal e Puerpério: atenção qualificada e humanizada - manual técnico. $3^{\mathrm{a}}$ ed. rev. Brasília: Ministério da Saúde, 2005.

5. Narchi NZ. Atenção pré-natal por enfermeiros na Zona Leste da cidade de São Paulo - Brasil. Rev Esc Enferm USP. 2010;44(2):266-73.

6. Albuquerque RA, Jorge MSB. Construção da autonomia no ato de cuidar das mulheres: sujeito autônomo ou sujeitado? Rev Baiana de Saúde Pública. 2010;34(2):397-408.

7. Zampieri MFM, Erdmann AL. Cuidado humanizado no pré-natal: um olhar para além das divergências e convergências. Rev Bras Saúde Matern Infant. 2010;10(3):359-67.

8. Cabral FB, Hirt LM, Van der Sand ICP. Atendimento pré-natal na ótica de puérperas: da medicalização à fragmentação do cuidado. Rev Esc Enferm USP. 2013;47(2):281-7.

9. Ministério da Saúde (BR). Saúde Brasil 2009: uma análise da situação de saúde e da agenda nacional e internacional de prioridades em saúde. Brasília: Ministério da Saúde, 2010.

10. Narchi NZ, Cruz EF, Gonçalves R. O papel das obstetrizes e enfermeiras obstetras na promoção da maternidade segura no Brasil. Ciênc Saúde Coletiva. 2013;18(4):1059-68.
11. Vieira SM, Bock LF, Zocche DA, Pessota CU. Percepção das puérperas sobre a assistência prestada pela equipe de saúde no pré-natal. Texto \& Contexto Enferm. 2011;20(Nesp):255-62

12. Narchi NZ. Exercise of essential competencies for midwifery care by nurses in São Paulo, Brazil. Midwifery. 2011;27(1):23-9.

13. Frigo LF, Silva RM, Mattos KM, Manfio F, Boeira GS. A importância dos grupos de gestante na atenção primária: um relato de experiência. Rev Epidemiol Control Infect. 2012;2(3):113-4.

14. Pinheiro BC, Bittar CML. Expectativas, percepções e experiências sobre o parto normal: relato de um grupo de mulheres. Fractal Rev Psicol. 2013;25(3):585-602.

15. Maron LC, Lagomarsino BS, Brizola NA, Van der Sand ICP, Cabral FB. Atividade grupal operativa com gestantes e familiares: um relato de experiência. Contexto \& Saúde. 2011;10(20):161-8.

16. Reberte LM, Hoga LAK. La experiencia de padres participantes de un grupo de educación en salud en la atención prenatal. Cienc Enferm. 2010;16(1):105-14.

17. Lefèvre F, Lefèvre AMC. O Discurso do Sujeito Coletivo: um novo enfoque em pesquisa qualitativa (desdobramentos). $2^{\mathrm{a}}$ ed. Caxias do Sul: Educs; 2005.

18. Conselho Nacional de Saúde (BR). Resolução $N^{\circ}$ 466 de 12 de dezembro de 2012 - Regulamenta a Resolução No 196/96 acerca das Diretrizes e Normas Regulamentadoras de Pesquisas Envolvendo Seres Humanos [Internet]. 2012 [acesso em 2014 Jan 10]. Disponível em: http://conselho.saude.gov.br/ resolucoes/2012/Reso466.pdf

19. Conselho Federal de Enfermagem (BR). Resolução No 311 de 08 de fevereiro de 2007 - Código de Ética dos Profissionais de Enfermagem [Internet]. 2007 [acesso em 2015 Jan 10]. Disponível em: http://novo. portalcofen.gov.br/resoluo-cofen-3112007_4345.html

20. Schwartz T, Vieira R, Geib LTC. Apoio social a gestantes adolescentes: desvelando percepções. Ciênc Saúde Coletiva. 2011;16(5):2575-85.

21. Instituto Brasileiro de Geografia e Estatística IBGE. Estimativas Projeções População [Internet]. 2008 [acesso em 2015 Jun 10]. Disponível em: ftp:// ftp.ibge.gov.br/Estimativas_Projecoes_Popuacao/ Revisao_2008_Projecoes_1980_2050/Revisao_2008_ Projecoes_1980_2050

22. Martinez EZ, Roza DL, Guimarães CG, Bava C, Achcar JA, Fabbro ALD. Gravidez na adolescência 
e características socioeconômias dos municípios do Estado de São Paulo, Brasil: análise espacial. Cad Saúde Pública. 201; 27(5):855-67.

23. Victora CG, Aquino EML, Lal MC, Monteiro CA, Barros FC, Szwarcwald CL. Saúde de mães e criançs no Brasil: progressos e desafios. The Lancet: Saúde no Brasil. 2011 [acesso em 2015 jun 12]. Disponível em: http:/download.thelancet.com/flatcontentassets/pdfs/ brazil/brazilpor2.pdf

24. Cesar JA, Mendoza-Sassi RA, Gonzalez-Chica DA, Mano OS, Goulart-Filha SM. Características sociodemográficas e de assistência à gestação e ao parto no extremo sul do Brasil. Cad Saúde Pública. 2011;27(5):985-94.

25. Mendoza-Sassi RA, Cesar JA, Silva PR, Denardin G, Mendes M. Risk factors for cesarean section by category of health service. Rev Saúde Pública. 2010;44(1):80-9.

26. Sanches NC, Mamede FV, Vivancos RBZ. Perfil das mulheres submetidas à cesareana e assistência obstétrica na maternidade pública em Ribeirão Preto. Texto \& Contexto Enferm. 2012;21(2):418-26.

27. Agência Nacional de Saúde Suplementar (BR). Brasil tem uma das maiores taxas de cesariana na Saúde Suplementar. Brasília: Ministério da Saúde; 2006 [acesso em 2015 Jun 22]. Disponível em: http://www. ans.gov.br/portal/site/home2/destaque_22585_2.asp

28. Ministério da Saúde (BR). MS capacita profissionais para atender mães e bebês. Brasília: Ministério da Saúde; 2009 [acesso em 2015 Jun 22]. Disponível em: http://portal.saude.gov.br/portal/aplicacoes/ noticias/default.cfm?pg=dspDetalheNoticia\&id area $=124 \& C O \_$NOTICIA $=10229$

29. World Health Organization - WHO. Appropriate technology for birth. Lancet. 1985;2(8452):436-7.

30. Montenegro CAB, Rezende Filho J. Rezende Obstetrícia fundamental. $13^{\mathrm{a}}$ ed. Rio de Janeiro: Guanabara Koogan; 2014.
31. Diniz D, Medeiros M. Aborto no Brasil: uma pesquisa domiciliar com técnica de urna. Ciênc Saúde Coletiva. 2010;15(Supl 1):959-66.

32. Demitto MO, Silva TC, Páschoa ARZ, Mathias TAF, Bercini LO. Orientações sobre amamentação na assistência pré-natal: uma revisão integrativa Rev Rene. 2010;11(Nesp):223-9.

33. Souza VB, Roecker S, Marcon SS. Ações educativas durante a assistência pré-natal: percepção de gestantes atendidas na rede básica de Maringá-PR. Rev Eletrônica Enferm. 2011;13(2):199-210.

34. Secretaria da Saúde do Estado de São Paulo. Atenção à gestante e à puérpera no SUS-SP: manual técnico do pré-natal e puerpério. São Paulo: SES/SP; 2010.

35. Francisquini AR, Higarashi IH, Serafim D, Bercini LO. Orientações recebidas durante a gestação, parto e pósparto por um grupo de puérperas. Ciênc Cuid Saúde. 2010;9(4):743-75.

36. Zampieri MFM, Gregório VRP, Custódio ZAO, Regis MI, Brasil C. Processo educativo com gestantes e casais grávidos: possibilidade para transformação e reflexão da realidade. Texto \& Contexto Enferm. 2010;19(4):719-27.

37. Van der Sand ICP, Campos IFA, Dreher DZ, Rios KR. Metodologia de atenção à gestante e família: relato de experiência com grupo operativo. Rev Enferm UFSM. 2011;1(3):497-505.

38. Duarte SJH, Borges AP, Arruda GL. Ações de enfermagem na educação em saúde no pré-natal: relato de experiência de um projeto de extensão da Universidade Federal do Mato Grosso. Rev Enferm Cent Oeste Min. 2011;1(2):277-82.

\section{Endereço para correspondência:}

Amanda Haissa Barros Henriques

Rua Dr. Carlos Macieira, 73

Bairro JK

CEP: 58187-000 - Picuí - PB - Brasil

E-mail: amandahaissa@gmail.com 